\title{
Age-related annual decline of lung function in patients with COPD
}

\author{
This article was published in the following Dove Press journal: \\ International Journal of COPD \\ 30 December 2015 \\ Number of times this article has been viewed
}

\author{
Soo Jung Kim ${ }^{1,2}$ \\ Jinwoo Lee ${ }^{1,2}$ \\ Young Sik Park ${ }^{1,2}$ \\ Chang-Hoon Lee ${ }^{1,2}$ \\ Ho II Yoon ${ }^{1,3}$ \\ Sang-Min Lee ${ }^{1,2}$ \\ Jae-Joon Yim ${ }^{1,2}$ \\ Young Whan Kim ${ }^{1,2}$ \\ Sung Koo Han ${ }^{1,2}$ \\ Chul-Gyu Yoo ${ }^{1,2}$
}

'Department of Internal Medicine, Seoul National University College of Medicine, Seoul, ${ }^{2}$ Division of Pulmonary and Critical Care Medicine, Department of Internal Medicine, Seoul National University Hospital, Seoul, ${ }^{3}$ Division of Pulmonary and Critical Care Medicine, Department of Internal Medicine, Seoul National University Bundang Hospital, Seongnam-si, Gyeonggi-do, Republic of Korea
Correspondence: Chul-Gyu Yoo Division of Pulmonary and Critical Care Medicine, Department of Internal Medicine, Seoul National University Hospital, I0I Daehak-Ro, Jongno-Gu, Seoul I I 0-744, Republic of Korea

Tel +82 220723760

Fax +82 27629662

Email cgyoo@snu.ac.kr
Background: According to the Fletcher-Peto curve, rate of decline in forced expiratory volume in 1-second $\left(\mathrm{FEV}_{1}\right)$ accelerates as age increases. However, recent studies have not demonstrated that the rate of $\mathrm{FEV}_{1}$ decline accelerates with age among COPD patients. The objective of the study is to evaluate annual rate of $\mathrm{FEV}_{1}$ decline as age increases among COPD patients.

Methods: In this retrospective cohort study, we enrolled COPD patients who were followed up at two tertiary care university hospitals from January 2000 to August 2013. COPD was defined as post-bronchodilator $(\mathrm{BD}) \mathrm{FEV}_{1} /$ forced vital capacity $(\mathrm{FVC})$ of $<0.7$. All participants had more than two spirometries, including BD response. Age groups were categorized as follows: below versus above median age or four quartiles.

Results: A total of 518 participants ( $94.2 \%$ male; median age, 67 years; range, $42-90$ years) were included. Mean absolute and predictive values of post-BD FEV were $1.57 \pm 0.62 \mathrm{~L}$ and $52.53 \% \pm 18.29 \%$, respectively. Distribution of Global initiative for Chronic Obstructive Lung Disease groups did not show statistical differences between age groups categorized by two different criteria. After grouping the population by age quartiles, the rate of $\mathrm{FEV}_{1}$ decline was faster among older patients than younger ones whether expressed as absolute value $(-10.60 \pm 5.57 \mathrm{~mL} /$ year, $-15.84 \pm 6.01 \mathrm{~mL} /$ year, $-18.63 \pm 5.53 \mathrm{~mL} /$ year, $32.94 \pm 6.01 \mathrm{~mL} /$ year, respectively; $P=0.048)$ or predicted value $(-0.34 \% \pm 0.19 \% /$ year, $-0.53 \% \pm 0.21 \% /$ year, $-0.62 \% \pm 0.19 \%$ / year, $-1.26 \% \pm 0.21 \% /$ year, respectively, $P=0.010$ ).

Conclusion: As suggested conceptually by the Fletcher-Peto curve, annual FEV decline $_{1}$ among COPD patients is accelerated among older patients than younger ones.

Keywords: age, chronic obstructive lung disease, respiratory function tests

\section{Introduction}

Since the 1970 s, the idea that forced expiratory volume in 1-second $\left(\mathrm{FEV}_{1}\right)$ decline accelerates with age has been generally accepted. Fletcher and Peto ${ }^{1}$ suggested a model of lung function decline across the lifespan of an individual - the Fletcher-Peto curve. The Fletcher-Peto curve, which was obtained by extrapolating data from 792 men aged 30-59 years working in West London, showed that the rate of $\mathrm{FEV}_{1}$ decline accelerates slightly with age. Another cohort study, including participants from six eastern and midwestern cities in the United States, reported that the annual rate of $\mathrm{FEV}_{1}$ decline increased more rapidly with age in never smokers. ${ }^{2}$

Based on the Fletcher-Peto curve, $\mathrm{FEV}_{1}$ decline among COPD patients typically occurs more quickly than $\mathrm{FEV}_{1}$ decline among smoking non-COPD patients. At the same time, recent studies have showed the rate of $\mathrm{FEV}_{1}$ decline is highly variable among COPD patients. ${ }^{3,4}$ The Evaluation of COPD Longitudinally to Identify Predictive Surrogate Endpoints (ECLIPSE) observational study reported a wide range of annual change in $\mathrm{FEV}_{1}$, from a decrease of more than $40 \mathrm{~mL}$ to an increase of more than $20 \mathrm{~mL}$, among COPD patients. ${ }^{4}$ 
Many factors contributing to rapid $\mathrm{FEV}_{1}$ decline have been suggested among COPD patients. Previous studies reported that rates of decline were associated with smoking status, ${ }^{4-6}$ exposure to biomass, ${ }^{7}$ experience of acute exacerbation, ${ }^{4,5}$ bronchodilator (BD) reversibility, ${ }^{4}$ presence of emphysema, ${ }^{4}$ and body mass index (BMI). ${ }^{3}$ However, there is controversy about whether lung function decline accelerates with age among COPD patients, although age has been recognized as a factor contributing to rapid decline of $\mathrm{FEV}_{1}$.

The ECLIPSE observational study did not demonstrate an increasing rate of $\mathrm{FEV}_{1}$ decline with an increase in age among COPD patients. ${ }^{4}$ Another study reported that "rapid" decliners were significantly younger than "slow" decliners. ${ }^{3}$ More recent data showed a decline of lung function among younger patients with COPD was similar to that of older patients. ${ }^{89}$ However, these studies did not include patients with Global initiative for Chronic Obstructive Lung Disease (GOLD) stage I for $\mathrm{FEV}_{1}$ decline analysis, ${ }^{3,4}$ nor did they include all ages of COPD patients. Moreover, previous studies compared "rapid" with "slow" decliners, defined by extremes of distribution among individual rates of decline.

Therefore, it is still unclear whether age is a real factor influencing the rate of $\mathrm{FEV}_{1}$ decline among COPD patients. The objective of this study is to evaluate the differences of annual $\mathrm{FEV}_{1}$ decline among COPD patients of different ages.

\section{Materials and methods Subjects}

We enrolled the COPD patients who were followed up at two tertiary care university hospitals - the Seoul National University Hospital and Seoul National University Bundang Hospital during the period from January 2000 to August 2013.

All COPD diagnoses were confirmed with spirometry, defined by post-BD $\mathrm{FEV}_{1} / \mathrm{FVC}$ less than 0.7 . The COPD patients above 40 years of age were included if they had performed more than two spirometries, including BD response, during follow-up. Patients with lung cancer or a history of lung resection surgery were excluded.

\section{Study design}

A retrospective cohort study was performed. The study was reviewed and approved by the Institutional Review Board of both institutions and was performed in accordance with Good Clinical Practice guidelines (IRB number: H-1309-107-523, B-1406/212-105). The IRB granted a waiver of informed consent for our retrospective study.

Demographic and clinical data were collected from medical records. Serial measurements of spirometric values were collected during follow-up period. Both absolute and predicted values of spirometry were collected. The predicted values of $\mathrm{FVC}$ and $\mathrm{FEV}_{1}$ were calculated by published formula for Korean people, because when compared with predicted values for Caucasian populations, the predicted values were comparable or higher. ${ }^{10}$ Positive BD responsiveness was defined as more than $12 \%$ increase in $\mathrm{FEV}_{1}$, and more than $200 \mathrm{~mL}$ increase in $\mathrm{FEV}_{1}{ }^{11}$

The participants were categorized according to age as follow: below versus above the median age or four quartiles. Primary outcome was annual decline rate of post-BD FEV according to age, and secondary outcome was pre-BD FEV ${ }_{1}$.

Additionally, we analyzed the annual decline rate of post-BD FEV $\mathrm{F}_{1}$ in subgroup of individuals who satisfied a post-BD $\mathrm{FEV}_{1} / \mathrm{FVC}$ ratio below the lower limit of normal (LLN) due to concerns that some normal participants may be included in the older groups of this study when using fixed $\mathrm{FEV}_{1} / \mathrm{FVC}$ ratio. ${ }^{12}$

\section{Statistical analysis}

Continuous variables are presented as means ( \pm standard deviaiton [SD]), and categorical variables are expressed as relative frequencies and percentages. Age groups were compared using the chi-square test for continuous variables, or Student's $t$-test for categorical variables. A two-tailed $P$-value less than 0.05 indicated statistical significance. Annual changes in pre- and post-BD $\mathrm{FEV}_{1}$ for each age group were assessed using a multilevel mixed-effects linear regression model. It was adjusted for sex, body mass index, smoking status (current smokers, formal smokers, or never smokers), bronchodilator response, experience of acute exacerbation, and initial $\mathrm{FEV}_{1}$.

\section{Results \\ Study subjects}

Five hundred and eighteen patients with COPD were enrolled. Baseline characteristics and lung function are shown in Table 1. Among 518 participants, $94.2 \%$ of patients were male, and their median age was 67 years (range, $42-90$ years). Mean absolute and predicted values of post-BD FEV , were $_{1.57 \pm 0.62 \mathrm{~L}}$ and $52.53 \% \pm 18.29 \%$, respectively. On the basis of $\mathrm{FEV}_{1}$ severity using GOLD grade, ${ }^{13} 8.7 \%, 44.8 \%, 37.3 \%$, and $9.3 \%$ of patients distributed GOLD I, II, III, and IV, respectively. Mean duration of observation was $55.08 \pm 28.00$ months. Mean frequency of pulmonary function test was $0.57 \pm 0.29$ /year.

\section{Annual rate of $F E V$, decline in patients above versus below median age}

To evaluate whether $\mathrm{FEV}_{1}$ decline is accelerated among older COPD patients, we first categorized patients into two groups above and below the median age of 67 years. COPD patients 
Table I Baseline characteristics: below versus above the median age of 67 years

\begin{tabular}{|c|c|c|c|c|}
\hline & $\begin{array}{l}\text { Total patients } \\
(n=5 \mid 8)\end{array}$ & $\begin{array}{l}\text { Younger patients } \\
(n=235)\end{array}$ & $\begin{array}{l}\text { Older patients } \\
(n=283)\end{array}$ & $P$-value \\
\hline Sex, male & $488(94.2)$ & $225(95.7)$ & $263(92.9)$ & 0.173 \\
\hline $\mathrm{BMI}, \mathrm{kg} / \mathrm{m}^{2}$ & $22.52 \pm 3.30$ & $23.21 \pm 3.04$ & $21.95 \pm 3.39$ & $<0.001$ \\
\hline \multicolumn{5}{|l|}{ Smoking status } \\
\hline Current smoker & $219(42.3)$ & II (49.8) & $102(36.0)$ & 0.008 \\
\hline Former smoker & $224(43.2)$ & $87(37.0)$ & I 37 (48.4) & \\
\hline Never smoker & $33(6.4)$ & $14(6.0)$ & $19(6.7)$ & \\
\hline Unknown & $42(8.1)$ & $17(7.2)$ & $25(8.9)$ & \\
\hline Pack-year & $43.48 \pm 22.43$ & $40.57 \pm 19.37$ & $45.90 \pm 24.45$ & 0.006 \\
\hline GOLD & & & & 0.848 \\
\hline I & $45(8.7)$ & $24(10.2)$ & $21(7.4)$ & \\
\hline II & $232(44.8)$ & $102(43.4)$ & I 30 (45.9) & \\
\hline III & $193(37.3)$ & $85(32.6)$ & $108(38.2)$ & \\
\hline IV & $48(9.3)$ & $24(10.2)$ & $24(8.5)$ & \\
\hline \multicolumn{5}{|l|}{ Post-bronchodilator } \\
\hline FVC, L & $3.32 \pm 0.84$ & $3.59 \pm 0.85$ & $3.10 \pm 0.77$ & $<0.001$ \\
\hline FVC, \% & $80.35 \pm 16.72$ & $83.28 \pm 16.97$ & $77.92 \pm 16.14$ & $<0.001$ \\
\hline $\mathrm{FEV}_{1}, \mathrm{~L}$ & $1.57 \pm 0.62$ & $1.74 \pm 0.67$ & $1.43 \pm 0.53$ & $<0.001$ \\
\hline $\mathrm{FEV}_{1}, \%$ & $52.53 \pm 18.29$ & $53.22 \pm 18.79$ & $52.13 \pm 17.88$ & 0.501 \\
\hline $\mathrm{FEV}_{\mathrm{I}} / \mathrm{FVC}, \%$ & $46.83 \pm 11.58$ & $47.80 \pm 12.08$ & $46.02 \pm 11.10$ & 0.082 \\
\hline \multicolumn{5}{|l|}{ Pre-bronchodilator } \\
\hline FVC, L & $3.16 \pm 0.88$ & $3.4 I \pm 0.90$ & $2.95 \pm 0.80$ & $<0.001$ \\
\hline FVC, \% & $76.53 \pm 17.83$ & $79.06 \pm 18.45$ & $74.43 \pm 17.05$ & 0.003 \\
\hline $\mathrm{FEV}_{1}, \mathrm{~L}$ & $1.46 \pm 0.62$ & $1.62 \pm 0.69$ & $1.33 \pm 0.52$ & $<0.001$ \\
\hline $\mathrm{FEV}_{1}, \%$ & $48.94 \pm 18.69$ & $49.54 \pm 19.44$ & $48.45 \pm 18.06$ & 0.514 \\
\hline $\mathrm{FEV}_{1} / \mathrm{FVC}, \%$ & $45.59 \pm 11.56$ & $46.58 \pm 12.22$ & $44.77 \pm 10.94$ & 0.079 \\
\hline Positive BDR & $24(4.6)$ & $10(4.3)$ & $14(4.9)$ & 0.709 \\
\hline History of acute exacerbation & $174(33.6)$ & $63(26.8)$ & $111(39.2)$ & 0.003 \\
\hline Follow-up months & $55.08 \pm 28.00$ & $60.57 \pm 28.80$ & $50.53 \pm 26.52$ & $<0.001$ \\
\hline
\end{tabular}

Note: Data presented as mean \pm SD or $\mathrm{n}(\%)$.

Abbreviations: BDR, bronchodilator response; BMI, body mass index; FEV , forced expiratory volume in I-second; FVC, forced vital capacity; GOLD, Global initiative for Chronic Obstructive Lung Disease.

below the median age had lower BMI, more significant smoking history, and less experience of acute exacerbation than those above median age (Table 1 ). The distribution of $\mathrm{FEV}_{1}$ severity by GOLD stage was not significantly different between two groups $(P=0.848)$. Therefore, the annual rate of $\mathrm{FEV}_{1}$ decline among the two groups was compared after adjustment of the following covariates: sex, height, BMI, smoking status, experience of acute exacerbation, presence of BD response, and initial $\mathrm{FEV}_{1}$. Post-BD FEV ${ }_{1}$ declined more rapidly among older patients $(-13.01 \pm 4.10 \mathrm{~mL} /$ year versus $-25.04 \pm 4.01 \mathrm{~mL} /$ year, respectively, $P=0.036$ ), even when expressed as the predictive value in $\mathrm{FEV}_{1}(-0.40 \% \pm 0.12 \% /$ year versus $-0.90 \% \pm 0.12 \%$ / year, respectively, $P=0.003$ ). The rate of pre-BD FEV decline $_{1}$ was also faster among older patients, but less steep than that of post-BD FEV 1 (Table 2).

\section{Annual rate of $\mathrm{FEV}$, decline in quartiles of age}

Next, participants were divided into quartiles based on age. The numbers and ages of patients within each quartile group were as follows: Q1 ( $\mathrm{n}=128$, below 63 years), Q2 $(\mathrm{n}=107$, 63-67 years), Q3 ( $\mathrm{n}=141,67-72$ years), and Q4 $(\mathrm{n}=142$, above 72 years). The distribution of $\mathrm{FEV}_{1}$ severity by GOLD was not different between age groups $(P=0.490)$ (Table S1). The annual rate of $\mathrm{FEV}_{1}$ decline was also compared after adjustment of covariates. Annual decline in post-BD FEV increased $_{1}$ with increasing age, whether expressed as absolute value $(-10.60 \pm 5.57 \mathrm{~mL} /$ year, $-15.84 \pm 6.01 \mathrm{~mL} /$ year, $-18.63 \pm 5.53$ $\mathrm{mL} /$ year, $-32.94 \pm 6.01 \mathrm{~mL} /$ year, respectively, $P=0.048$ ) or predicted value $(-0.34 \% \pm 0.19 \% /$ year, $-0.53 \% \pm 0.21 \%$ / year, $-0.62 \% \pm 0.19 \% /$ year, $-1.26 \% \pm 0.21 \% /$ year, respectively, $P=0.010$ ) (Table 3 ).

\section{Annual rate of FEV , decline in subjects meeting the LLN criterion}

Among 518 patients, 481 patients had post-BD $\mathrm{FEV}_{1} /$ FVC ratio below the LLN. When patients were categorized according to median age, there was a trend toward greater $\mathrm{FEV}_{1}$ decline with age $(-13.17 \pm 4.19 \mathrm{~mL} / \mathrm{year}$ versus $-23.15 \pm 4.13 \mathrm{~mL} /$ year, $P=0.062$ ) (Table 4$)$. When 
Table 2 Lung function decline: below versus above the median age of 67 years

\begin{tabular}{|c|c|c|c|c|}
\hline & \multicolumn{2}{|l|}{ Unadjusted } & \multicolumn{2}{|l|}{ Adjusted } \\
\hline & Mean \pm SE & $P$-value & Mean \pm SE & $P$-value \\
\hline \multicolumn{5}{|l|}{$\mathrm{FEV}_{1}, \mathrm{~mL} /$ year } \\
\hline \multicolumn{5}{|c|}{ Post-bronchodilator } \\
\hline Younger & $-12.60 \pm 3.56$ & 0.021 & $-13.01 \pm 4.10$ & $0.036^{\mathrm{a}}$ \\
\hline Older & $-24.24 \pm 3.57$ & & $-25.04 \pm 4.01$ & \\
\hline \multicolumn{5}{|c|}{ Pre-bronchodilator } \\
\hline Younger & $-6.45 \pm 3.53$ & 0.009 & $-6.97 \pm 3.79$ & $0.022^{\mathrm{a}}$ \\
\hline Older & $-19.55 \pm 3.57$ & & $-19.22 \pm 3.79$ & \\
\hline \multicolumn{5}{|l|}{$\mathrm{FEV}_{1}$, \%/year } \\
\hline \multicolumn{5}{|c|}{ Post-bronchodilator } \\
\hline Younger & $-0.42 \pm 0.11$ & 0.004 & $-0.40 \pm 0.12$ & $0.003^{b}$ \\
\hline Older & $-0.90 \pm 0.12$ & & $-0.90 \pm 0.12$ & \\
\hline \multicolumn{5}{|c|}{ Pre-bronchodilator } \\
\hline Younger & $-0.22 \pm 0.12$ & 0.001 & $-0.21 \pm 0.14$ & $0.008^{\mathrm{b}}$ \\
\hline Older & $-0.76 \pm 0.12$ & & $-0.74 \pm 0.14$ & \\
\hline
\end{tabular}

Notes: adjusted for sex, body mass index, smoking status, bronchodilator response, experience of acute exacerbation, and initial $\mathrm{FEV}_{1} .{ }^{\text {b Adjusted for smoking }}$ status, bronchodilator response, experience of acute exacerbation, and initial FEV, Abbreviations: $\mathrm{FEV}_{1}$, forced expiratory volume in I-second; SE, standard error.

Table 3 Lung function decline according to age quartile

\begin{tabular}{|c|c|c|c|c|}
\hline & \multicolumn{2}{|l|}{ Unadjusted } & \multicolumn{2}{|l|}{ Adjusted } \\
\hline & Mean \pm SE & $P$-value & Mean \pm SE & $P$-value \\
\hline \multicolumn{5}{|c|}{$\mathrm{FEV}_{1}, \mathrm{~mL} /$ year } \\
\hline \multicolumn{5}{|c|}{ Post-bronchodilator } \\
\hline QI & $-10.62 \pm 4.84$ & 0.048 & $-10.60 \pm 5.57$ & $0.048^{\mathrm{a}}$ \\
\hline Q2 & $-14.82 \pm 5.24$ & & $-15.84 \pm 6.01$ & \\
\hline Q3 & $-|9.7| \pm 4.7 \mid$ & & $-18.63 \pm 5.53$ & \\
\hline Q4 & $-30.34 \pm 5.46$ & & $-32.94 \pm 6.01$ & \\
\hline \multicolumn{5}{|c|}{ Pre-bronchodilator } \\
\hline QI & $-4.99 \pm 4.78$ & 0.029 & $-4.9 I \pm 5.66$ & $0.044^{a}$ \\
\hline Q2 & $-8.17 \pm 5.21$ & & $-8.09 \pm 6.10$ & \\
\hline Q3 & $-15.26 \pm 4.69$ & & $-13.78 \pm 5.45$ & \\
\hline Q4 & $-25.45 \pm 5.50$ & & $-27.35 \pm 6.18$ & \\
\hline \multicolumn{5}{|c|}{$\mathrm{FEV}_{1}, \% /$ year } \\
\hline \multicolumn{5}{|c|}{ Post-bronchodilator } \\
\hline QI & $-0.33 \pm 0.16$ & 0.005 & $-0.34 \pm 0.19$ & $0.010^{\mathrm{b}}$ \\
\hline Q2 & $-0.50 \pm 0.17$ & & $-0.53 \pm 0.21$ & \\
\hline Q3 & $-0.68 \pm 0.16$ & & $-0.62 \pm 0.19$ & \\
\hline Q4 & $-1.17 \pm 0.18$ & & $-1.26 \pm 0.21$ & \\
\hline \multicolumn{5}{|c|}{ Pre-bronchodilator } \\
\hline QI & $-0.18 \pm 0.16$ & 0.002 & $-0.17 \pm 0.19$ & $0.007^{\mathrm{b}}$ \\
\hline Q2 & $-0.28 \pm 0.17$ & & $-0.27 \pm 0.21$ & \\
\hline Q3 & $-0.54 \pm 0.15$ & & $-0.47 \pm 0.18$ & \\
\hline Q4 & $-1.04 \pm 0.18$ & & $-1.08 \pm 0.21$ & \\
\hline
\end{tabular}

Notes: The numbers and ages of patients within each quartile group were as follows: QI ( $n=128$, below 63 years), Q2 ( $n=107,63-67$ years), Q3 ( $n=141$, 67-72 years), and Q4 ( $\mathrm{n}=142$, above 72 years). adjusted for sex, body mass index, smoking status, bronchodilator response, experience of acute exacerbation, and initial $\mathrm{FEV}_{1} .{ }^{\mathrm{b}}$ Adjusted for smoking status, bronchodilator response, experience of acute exacerbation, and initial FEV,

Abbreviations: $\mathrm{FEV}_{1}$, forced expiratory volume in I-second; SE, standard error.
Table 4 Annual rate of post-bronchodilator FEV, decline in subjects meeting the lower limit of normal criterion

\begin{tabular}{|c|c|c|c|c|}
\hline & \multicolumn{2}{|l|}{ Unadjusted } & \multicolumn{2}{|l|}{ Adjusted } \\
\hline & Mean \pm SE & $P$-value & Mean \pm SE & $P$-value \\
\hline \multicolumn{5}{|c|}{ According to median age } \\
\hline \multicolumn{5}{|c|}{$\mathrm{FEV}_{1}, \mathrm{~mL} /$ year } \\
\hline Younger & $-11.79 \pm 3.64$ & 0.053 & $-13.17 \pm 4.19$ & $0.062^{\mathrm{a}}$ \\
\hline Older & $-21.83 \pm 3.68$ & & $-23.15 \pm 4.13$ & \\
\hline \multicolumn{5}{|l|}{$\mathrm{FEV}_{1}$, \%/year } \\
\hline Younger & $-0.39 \pm 0.12$ & 0.017 & $-0.40 \pm 0.15$ & $0.039^{b}$ \\
\hline Older & $-0.80 \pm 0.12$ & & $-0.83 \pm 0.14$ & \\
\hline \multicolumn{5}{|c|}{ According to age quartile } \\
\hline \multicolumn{5}{|c|}{$\mathrm{FEV}_{1}, \mathrm{~mL} /$ year } \\
\hline QI & $-10.62 \pm 5.22$ & 0.113 & $-11.11 \pm 6.03$ & $0.085^{\mathrm{a}}$ \\
\hline Q2 & $-12.87 \pm 5.05$ & & $-13.17 \pm 5.79$ & \\
\hline Q3 & $-17.40 \pm 4.80$ & & $-16.67 \pm 5.47$ & \\
\hline Q4 & $-28.12 \pm 5.70$ & & $-31.43 \pm 6.28$ & \\
\hline \multicolumn{5}{|l|}{$\mathrm{FEV}_{1}$, \%/year } \\
\hline QI & $-0.33 \pm 0.17$ & 0.021 & $-0.34 \pm 0.21$ & $0.023^{b}$ \\
\hline Q2 & $-0.50 \pm 0.17$ & & $-0.46 \pm 0.20$ & \\
\hline Q3 & $-0.60 \pm 0.16$ & & $-0.55 \pm 0.19$ & \\
\hline Q4 & $-1.08 \pm 0.19$ & & $-1.20 \pm 0.22$ & \\
\hline
\end{tabular}

Notes: The numbers and ages of patients within each quartile group were as follows: Q1 ( $n=107$, below 62 years), Q2 ( $n=115,62-67$ years), Q3 $(n=133$,

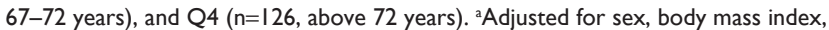
smoking status, bronchodilator response, experience of acute exacerbation, and initial $\mathrm{FEV}_{1}$. ${ }^{\mathrm{b}} \mathrm{Adjusted}$ for smoking status, bronchodilator response, experience of acute exacerbation, and initial $\mathrm{FEV}_{\text {, }}$.

Abbreviations: $\mathrm{FEV}_{1}$, forced expiratory volume in I-second; SE, standard error.

$\mathrm{FEV}_{1}$ was expressed as a percentage of the predictive value, post-BD $\mathrm{FEV}_{1}$ declined more rapidly in older patients $(-0.40 \% \pm 0.15 \% /$ year versus $-0.83 \% \pm 0.14 \%$ /year, respectively, $P=0.039$ ). Dividing participants into quartile groups based on age demonstrated consistent results whether expressed as absolute value $(-11.11 \pm 6.03 \mathrm{~mL} /$ year, $-13.17 \pm 5.79 \mathrm{~mL} /$ year, $-16.67 \pm 5.47 \mathrm{~mL} /$ year, $-31.43 \pm 6.28$ $\mathrm{mL} /$ year, respectively, $P=0.085$ ), or predicted value $(-0.34 \% \pm 0.21 \% /$ year, $-0.46 \% \pm 0.20 \% /$ year, $-0.55 \% \pm 0.19 \%$ / year, $-1.20 \% \pm 0.22 \% /$ year, respectively, $P=0.023$ ).

\section{Discussion}

Previous studies showed an accelerated decline in $\mathrm{FEV}_{1}$ with age among healthy participants. A prospective epidemiological study by Fletcher and Peto, ${ }^{1}$ which evaluated 1,136 working men aged 35-59 years over an 8-year follow-up period, demonstrated that $\mathrm{FEV}_{1}$ falls gradually over a lifetime, and the rate of $\mathrm{FEV}_{1}$ decline accelerates slightly with age. Ware et $\mathrm{al}^{2}$ reported that annual rate of $\mathrm{FEV}_{1}$ decline was higher among elderly non-smokers: $12.9 \mathrm{~mL} /$ year at age 25 years versus $58.2 \mathrm{~mL} /$ year at age 75 years. In more recent crosssectional and longitudinal studies, an accelerated decline in $\mathrm{FEV}_{1}$ with age was also reported in never-smoker patients. ${ }^{14,15}$ 
Sandford et $\mathrm{al}^{16}$ reported that among smokers, rapid decline was associated with older age compared with non-decline. These results suggest an accelerated decline of $\mathrm{FEV}_{1}$ with aging among non-COPD patients.

Thus, it can be speculated that decline of $\mathrm{FEV}_{1}$ among COPD patients is also accelerated with age. However, it has not been clear whether $\mathrm{FEV}_{1}$ is also accelerated among aged COPD patients compared with young COPD patients. Recent studies have not demonstrated that the rate of $\mathrm{FEV}_{1}$ decline accelerates with age among COPD patients. Casanova et $\mathrm{al}^{3}$ defined decliners with significant slope as patients showing a statistically significant annual loss of $\mathrm{FEV}_{1}(-86 \mathrm{~mL} /$ year; $95 \%$ confidence interval, -32 to $-278 \mathrm{~mL} /$ year) and decliners with nonsignificant slope as those who demonstrated a nonstatistically significant annual $\mathrm{FEV}_{1}$ decline ( $-28 \mathrm{~mL} /$ year; $95 \%$ confidence interval, +9 to $-214 \mathrm{~mL} /$ year). They demonstrated that rapid decliners with significant slope were younger, compared with nonstatistically significant slope decliners (64 \pm 9 years versus $66 \pm 9$ years, $P=0.018$, respectively). However, unlike our study, they categorized participants according to the rate of $\mathrm{FEV}_{1}$ decline and not by age, which may have affected the results. In addition, the proportion of decliner with significant slope was small (18\%), and the range of annual rate of $\mathrm{FEV}_{1}$ decline in our study was approximately 10-33 mL/year, which is much lower than that of significant slope decliners in the previous study. These factors may also have influenced the results. Furthermore, Casanova et $\mathrm{al}^{3}$ also reported that rapid decliners had a lower BMI and better lung function at baseline. However, after multivariate logistic regression including age, sex, pack-years, smoking habit, comorbidity, and annual hospital exacerbation rate, higher level of FEV and low BMI at baseline were the only two independent and significant predictors of $\mathrm{FEV}_{1}$ decline and they failed to show association between age and $\mathrm{FEV}_{1}$ decline.

In contrast, Nishimura et $\mathrm{al}^{8}$ reported that mean age was not significantly different between rapid decliner and slow decliner ( $69 \pm 6$ years versus $70 \pm 8$ years, $P=0.11$, respectively). This trial had limitation and categorized all patients into only three groups by rate of $\mathrm{FEV}_{1}$ decline. Vestbo et $\mathrm{al}^{4}$ reported that age was not associated with the rate of decline of $\mathrm{FEV}_{1}$ in the ECLIPSE cohort. However, this study did not include COPD patients with GOLD stage I disease. A more recent study evaluated progression of $\mathrm{FEV}_{1}$ among younger ( $\leq 55$ years) and older ( $\geq 65$ years) COPD patients. ${ }^{9}$ They reported that average annual rate of $\mathrm{FEV}_{1}$ decline was similar among younger and older COPD patients $(38.8 \mathrm{~mL} /$ year versus $40.6 \mathrm{~mL} /$ year, respectively; $P=0.86$ ). In this study, the proportion of GOLD stage I was higher among younger
COPD patients. It could affect the rate of $\mathrm{FEV}_{1}$ decline because it appears to be inversely related to the GOLD stage. ${ }^{17,18}$ Moreover, COPD patients between the ages of 55 years and 65 years were not included. Different results in these studies might be due to different inclusion criteria.

When compared with previous trials, our study included all COPD patients between the ages of 42 and 90 years. GOLD stage I COPD patients were also included in our study, and the distribution of GOLD stage and predictive values of $\mathrm{FEV}_{1}$ were not different between age groups. To minimize the effect of arbitrary categorization of age groups on the rate of $\mathrm{FEV}_{1}$ decline, participants were categorized according to age by two different criteria: median age and quartiles of age. After categorizing patients into age groups based on median age or quartile, acceleration of $\mathrm{FEV}_{1}$ decline with aging was observed.

Additionally, we performed further analysis categorizing patients into groups with 10-year intervals (Table S2). When the data were expressed as predictive values, the rate

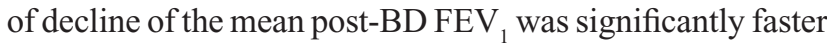
among older patients, when compared with younger patients $(-0.39 \% \pm 0.80 \% /$ year,$-0.24 \% \pm 0.24 \% /$ year,$-0.61 \% \pm 0.14 \% /$ year, $-0.83 \% \pm 0.19 \% /$ year, $-2.00 \% \pm 0.46 \% /$ year, respectively; $P=0.015$ ) (Table S3). Only seven patients were allocated to the youngest age group, and it might explain why the 40- to 49-year-old group showed higher rates of $\mathrm{FEV}_{1}$ decline.

It could be argued that our results were the effect of regression-to-the-mean phenomenon. Regression-to-themean is the phenomenon that if a variable is extreme on its first measurement, it will tend to be closer to the average on its next measurement. In our study, although it did not reach statistical significance, older patients showed slightly higher proportion of GOLD III-IV (Table 1), suggesting the possibility of better $\mathrm{FEV}_{1}$ in younger group. In fact, the absolute initial value of $\mathrm{FEV}_{1}$ was higher in the younger group than that in the older group (Tables 1, S1, and S2). Thus, according to regression-to-the-mean, higher initial $\mathrm{FEV}_{1}$ value in younger patients would be followed by the lower $\mathrm{FEV}_{1}$ value on next measurement, resulting in more rapid decline of $\mathrm{FEV}_{1}$ compared with older patients. However, our result is opposite, that is, faster $\mathrm{FEV}_{1}$ decline in older groups. Therefore, our result of faster $\mathrm{FEV}_{1}$ decline in younger group seems less likely to be due to regression-to-the-mean phenomenon.

Absolute value of $\mathrm{FEV}_{1}$ has been conventionally used for analysis of lung function decline in COPD patients. ${ }^{3,4,8,9,19}$ However, the Toward a Revolution in COPD Health (TORCH) study demonstrated that the trend of $\mathrm{FEV}_{1}$ decline was preserved when $\mathrm{FEV}_{1}$ decline was expressed as predictive 
value. ${ }^{20}$ In this study, the rate of $\mathrm{FEV}_{1}$ decline was expressed not only as absolute value, but also as predictive value. Change of absolute value of $\mathrm{FEV}_{1}$ could be underestimated in older patients, because absolute value of $\mathrm{FEV}_{1}$ among old patients was lower than among younger patients. Therefore, predictive value of $\mathrm{FEV}_{1}$ could be a more appropriate measure of the decline of FEV $\mathrm{F}_{1}$ than absolute value. Thomsen et $\mathrm{al}^{21}$ reported that relative changes of $\mathrm{FEV}_{1}$ seem to explain changes in lung function better than absolute measurement among heavy smokers.

We used pre-BD $\mathrm{FEV}_{1}$, as well as post-BD $\mathrm{FEV}_{1}$, to evaluate the rate of decline in $\mathrm{FEV}_{1}$. Interestingly, the rate of

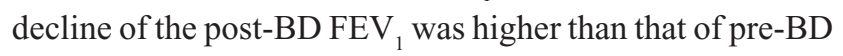
$\mathrm{FEV}_{1}$ among all age groups. This observation is consistent with findings in previous studies. ${ }^{22,23}$ Tashkin et $\mathrm{al}^{23}$ reported that the slopes of post-BD FEV ${ }_{1}$ were significantly steeper than the slopes calculated from the pre-BD measurements. In addition, post hoc analysis of data from the Long-Term Impacts on Function with Tiotropium (UPLIFT) trial demonstrated that $\mathrm{FEV}_{1}$ response to bronchodilators declined significantly over time, and the rate of $\mathrm{FEV}_{1}$ decline was generally more significant among older patients. Development of tolerance to bronchodilator therapy over the course of the disease could be an explanation for the rapid decline in post-BD lung function. ${ }^{24}$

Our study has some limitations. First of all, as our study design was retrospective, we could not directly evaluate the effect of treatment regimens. Instead, because prescribed medications vary as the years go by, we analyzed the rate of $\mathrm{FEV}_{1}$ decline in each group by adding "year of diagnosis" as variable for adjustment. When patients were categorized into quartiles, the annual decline in post-BD $\mathrm{FEV}_{1}$ was still accelerated with age, whether expressed as absolute value or predicted value. Next, over-adjustment for baseline $\mathrm{FEV}_{1}$ may be of concern. However, this method has already been used in previous studies including a post hoc analysis of the TORCH study. ${ }^{20}$ Third, patients with spirometries at irregular intervals were excluded, which might have introduced a selection bias. However, excluding irregular spirometries could also decrease bias because it is possible that spirometries were performed irregularly during an acute event.

Despite some of the aforementioned limitations, to our knowledge, this is the first study that includes COPD patients of all ages and all GOLD severity stages to evaluate the annual decline of $\mathrm{FEV}_{1}$ across age groups. This study demonstrated that the rate of decline among both post-BD and

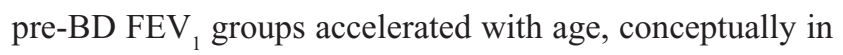
accordance with the Fletcher-Peto curve.

\section{Conclusion}

Conceptually, in accordance with the Fletcher-Peto curve, annual rates of $\mathrm{FEV}_{1}$ decline, whether expressed as absolute or predictive values, accelerate with increasing age among patients with COPD.

\section{Disclosure}

The authors report no conflicts of interest in this work.

\section{References}

1. Fletcher C, Peto R. The natural history of chronic airflow obstruction. Br Med J. 1977;1(6077):1645-1648.

2. Ware JH, Dockery DW, Louis TA, et al. Longitudinal and crosssectional estimates of pulmonary function decline in never-smoking adults. Am J Epidemiol. 1990;132(4):685-700.

3. Casanova C, de Torres JP, Aguirre-Jaime A, et al. The progression of chronic obstructive pulmonary disease is heterogeneous: the experience of the BODE cohort. Am J Respir Crit Care Med. 2011;184(9):1015-1021.

4. Vestbo J, Edwards LD, Scanlon PD, et al. Changes in forced expiratory volume in 1 second over time in COPD. N Engl J Med. 2011;365(13): $1184-1192$.

5. Kesten S, Celli B, Decramer M, et al. Adverse health consequences in COPD patients with rapid decline in $\mathrm{FEV}_{1}$-evidence from the UPLIFT trial. Respir Res. 2011;12:129.

6. Anthonisen NR, Connett JE, Kiley JP, et al. Effects of smoking intervention and the use of an inhaled anticholinergic bronchodilator on the rate of decline of FEV ${ }_{1}$. The Lung Health Study. JAMA. 1994;272(19): $1497-1505$.

7. Ramirez-Venegas A, Sansores RH, Quintana-Carrillo RH, et al. FEV decline in patients with chronic obstructive pulmonary disease associated with biomass exposure. Am J Respir Crit Care Med. 2014;190(9): 996-1002.

8. Nishimura M, Makita H, Nagai K, et al. Annual change in pulmonary function and clinical phenotype in chronic obstructive pulmonary disease. Am J Respir Crit Care Med. 2012;185(1):44-52.

9. Sanchez-Salcedo P, Divo M, Casanova C, et al. Disease progression in young patients with COPD: rethinking the Fletcher and Peto model. Eur Respir J. 2014;44(2):324-331.

10. Choi JK, Paek D, Lee JO. Normal predictive values of spirometry in Korean population. Tuberc Respir Dis. 2005;58(3):230-242.

11. Pellegrino R, Viegi G, Brusasco V, et al. Interpretative strategies for lung function tests. Eur Respir J. 2005;26(5):948-968.

12. Hardie JA, Buist AS, Vollmer WM, et al. Risk of over-diagnosis of COPD in asymptomatic elderly never-smokers. Eur Respir J. 2002; 20(5):1117-1122.

13. Vestbo J, Hurd SS, Agusti AG, et al. Global strategy for the diagnosis, management, and prevention of chronic obstructive pulmonary disease: GOLD executive summary. Am J Respir Crit Care Med. 2013;187(4): 347-365.

14. Janssens JP, Pache JC, Nicod LP. Physiological changes in respiratory function associated with ageing. Eur Respir J. 1999;13(1):197-205.

15. Brandli O, Schindler C, Kunzli N, et al. Lung function in healthy never smoking adults: reference values and lower limits of normal of a Swiss population. Thorax. 1996;51(3):277-283.

16. Sandford AJ, Chagani T, Weir TD, et al. Susceptibility genes for rapid decline of lung function in the lung health study. Am J Respir Crit Care Med. 2001;163(2):469-473.

17. Tantucci C, Modina D. Lung function decline in COPD. Int J Chron Obstruct Pulmon Dis. 2012;7:95-99.

18. Jenkins CR, Jones PW, Calverley PM, et al. Efficacy of salmeterol/ fluticasone propionate by GOLD stage of chronic obstructive pulmonary disease: analysis from the randomised, placebo-controlled TORCH study. Respir Res. 2009;10:59. 
19. Decramer M, Celli B, Kesten S, et al. Effect of tiotropium on outcomes in patients with moderate chronic obstructive pulmonary disease (UPLIFT): a prespecified subgroup analysis of a randomised controlled trial. Lancet. 2009;374(9696):1171-1178.

20. Celli BR, Thomas NE, Anderson JA, et al. Effect of pharmacotherapy on rate of decline of lung function in chronic obstructive pulmonary disease: results from the TORCH study. Am J Respir Crit Care Med. 2008;178(4):332-338.

21. Thomsen LH, Dirksen A, Shaker SB, et al. Analysis of FEV decline in relatively healthy heavy smokers: implications of expressing changes in $\mathrm{FEV}_{1}$ in relative terms. COPD. 2014;11(1):96-104.
22. Morice AH, Celli B, Kesten S, et al. COPD in young patients: a prespecified analysis of the four-year trial of tiotropium (UPLIFT). Respir Med. 2010;104(11):1659-1667.

23. Tashkin DP, Li N, Halpin D, et al. Annual rates of change in pre- vs post-bronchodilator $\mathrm{FEV}_{1}$ and $\mathrm{FVC}$ over 4 years in moderate to very severe COPD. Respir Med. 2013;107(12):1904-1911.

24. Tashkin DP, Li N, Kleerup EC, et al. Acute bronchodilator responses decline progressively over 4 years in patients with moderate to very severe COPD. Respir Res. 2014;15:102. 


\section{Supplementary materials}

Table SI Baseline characteristics according to age quartile

\begin{tabular}{|c|c|c|c|c|c|}
\hline & $\begin{array}{l}\text { QI (below } 63 \text { years, } \\
n=\mid 28 \text { ) }\end{array}$ & $\begin{array}{l}\text { Q2 (63-67 years, } \\
n=107)\end{array}$ & $\begin{array}{l}\text { Q3 (67-72 years, } \\
n=\mid 4 I)\end{array}$ & $\begin{array}{l}\text { Q4 (above } 72 \text { years, } \\
n=142 \text { ) }\end{array}$ & $P$-value \\
\hline Sex, male & $123(96.1)$ & $102(95.3)$ & $132(93.6)$ & $13 \mid(92.3)$ & 0.145 \\
\hline $\mathrm{BMI}, \mathrm{kg} / \mathrm{m}^{2}$ & $23.49 \pm 2.93$ & $22.88 \pm 3.16$ & $22.20 \pm 3.51$ & $21.71 \pm 3.26$ & $<0.001$ \\
\hline Smoking status & & & & & 0.407 \\
\hline Current smoker & $76(59.4)$ & $41(38.3)$ & $54(38.3)$ & $48(33.8)$ & \\
\hline Former smoker & $35(27.3)$ & $52(48.6)$ & $62(44.0)$ & $75(58.2)$ & \\
\hline Never smoker & $9(7.0)$ & $5(4.7)$ & $8(5.7)$ & II (7.7) & \\
\hline Unknown & $8(6.3)$ & $9(8.4)$ & $17(12.1)$ & $8(5.6)$ & \\
\hline Pack-year & $39.65 \pm 20.80$ & $41.66 \pm 17.55$ & $45.92 \pm 23.13$ & $45.89 \pm 25.77$ & 0.051 \\
\hline GOLD & & & & & 0.490 \\
\hline I & $12(9.4)$ & $12(11.2)$ & $7(5.0)$ & $14(9.9)$ & \\
\hline ॥ & $58(45.3)$ & $44(4 I . I)$ & $61(43.3)$ & $69(48.6)$ & \\
\hline III & $43(33.6)$ & $42(39.3)$ & $56(39.7)$ & $52(36.6)$ & \\
\hline IV & 15 (1I.7) & $9(8.4)$ & $17(12.1)$ & $7(4.9)$ & \\
\hline \multicolumn{6}{|l|}{ Post-bronchodilator } \\
\hline FVC, L & $3.68 \pm 0.85$ & $3.47 \pm 0.83$ & $3.10 \pm 0.75$ & $3.10 \pm 0.84$ & $<0.001$ \\
\hline FVC, \% & $83.62 \pm 16.74$ & $82.88 \pm|7.3|$ & $76.73 \pm 15.78$ & $79.10 \pm 16.46$ & 0.002 \\
\hline $\mathrm{FEV}_{1}, \mathrm{~L}$ & $1.8 \mathrm{I} \pm 0.69$ & $1.65 \pm 0.64$ & $1.4 \mathrm{I} \pm 0.52$ & $1.44 \pm 0.53$ & $<0.001$ \\
\hline $\mathrm{FEV}_{1}, \%$ & $53.27 \pm 18.86$ & $53.16 \pm 18.79$ & $48.92 \pm 16.79$ & $55.32 \pm|8.4|$ & 0.027 \\
\hline $\mathrm{FEV}_{\mathrm{I}} / \mathrm{FVC}, \%$ & $48.52 \pm 11.97$ & $46.93 \pm \mid 2.21$ & $45.53 \pm 11.05$ & $46.5 \mathrm{I} \pm 1 \mathrm{I} .17$ & 0.203 \\
\hline \multicolumn{6}{|l|}{ Pre-bronchodilator } \\
\hline FVC, L & $3.49 \pm 0.91$ & $3.3 \mathrm{I} \pm 0.88$ & $2.95 \pm 0.76$ & $2.97 \pm 0.82$ & $<0.001$ \\
\hline FVC, \% & $79.20 \pm 18.22$ & $78.9| \pm| 8.8 \mid$ & $73.08 \pm 16.33$ & $75.78 \pm 17.69$ & 0.016 \\
\hline $\mathrm{FEV}_{1}, \mathrm{~L}$ & $1.69 \pm 0.72$ & $1.53 \pm 0.65$ & $1.31 \pm 0.52$ & $1.35 \pm 0.53$ & $<0.001$ \\
\hline $\mathrm{FEV}_{1}, \%$ & $49.70 \pm 19.64$ & $49.34 \pm 19.28$ & $45.17 \pm 16.82$ & $51.71 \pm 18.70$ & 0.027 \\
\hline $\mathrm{FEV}_{1} / \mathrm{FVC}, \%$ & $47.45 \pm 12.09$ & $45.54 \pm 12.37$ & $44.15 \pm 10.78$ & $45.39 \pm 11.10$ & 0.135 \\
\hline Positive BDR & $2(1.6)$ & $8(7.5)$ & $7(5.0)$ & $7(4.9)$ & 0.335 \\
\hline History of acute exacerbation & $26(20.3)$ & $37(34.6)$ & $47(33.3)$ & $64(45.1)$ & $<0.001$ \\
\hline Follow-up months & $61.32 \pm 30.80$ & $59.66 \pm 26.33$ & $56.63 \pm 26.10$ & $44.38 \pm 25.56$ & $<0.001$ \\
\hline
\end{tabular}

Note: Data presented as mean \pm SD or $\mathrm{n}(\%)$.

Abbreviations: BDR, bronchodilator response; BMI, body mass index; FEV ${ }_{1}$, forced expiratory volume in I-second; FVC, forced vital capacity; GOLD, Global initiative for Chronic Obstructive Lung Disease. 
Table S2 Baseline characteristics: $40-90$ years of age

\begin{tabular}{|c|c|c|c|c|c|c|}
\hline & $\begin{array}{l}40-49 \\
(n=7)\end{array}$ & $\begin{array}{l}50-59 \\
(n=77)\end{array}$ & $\begin{array}{l}60-69 \\
(n=241)\end{array}$ & $\begin{array}{l}70-79 \\
(n=159)\end{array}$ & $\begin{array}{l}80-90 \\
(n=32)\end{array}$ & $P$-value \\
\hline Sex, male & $7(100)$ & 77 (97.5) & 227 (94.2) & $150(94.3)$ & $27(84.4)$ & 0.145 \\
\hline $\mathrm{BMI}, \mathrm{kg} / \mathrm{m}^{2}$ & $20.86 \pm 3.28$ & $23.57 \pm 2.82$ & $22.84 \pm 3.37$ & $21.72 \pm 3.07$ & $21.94 \pm 3.94$ & $<0.001$ \\
\hline Smoking & & & & & & 0.253 \\
\hline Current smoker & $3(42.9)$ & 47 (59.5) & $105(43.6)$ & $57(35.8)$ & $7(21.9)$ & \\
\hline Former smoker & 3 (42.9) & $22(27.8)$ & $102(42.3)$ & $78(49.1)$ & $19(59.4)$ & \\
\hline Never smoker & I (I4.3) & $4(5.1)$ & $13(5.4)$ & $10(6.3)$ & $5(15.6)$ & \\
\hline Unknown & $0(0)$ & $6(7.6)$ & $21(8.7)$ & $14(8.8)$ & $I(3.1)$ & \\
\hline Pack-year & $29.80 \pm 16.88$ & $41.77 \pm 20.46$ & $42.98 \pm 20.61$ & $46.5 \mathrm{I} \pm 25.42$ & $39.43 \pm 24.15$ & 0.129 \\
\hline GOLD & & & & & & 0.219 \\
\hline 1 & $0(0)$ & $7(8.9)$ & $20(8.3)$ & $16(10.1)$ & $2(6.3)$ & \\
\hline II & 3 (42.9) & $34(43.0)$ & $110(45.6)$ & $67(42.1)$ & $18(56.3)$ & \\
\hline III & $3(42.9)$ & $29(36.7)$ & $85(35.3)$ & $65(40.9)$ & II (34.4) & \\
\hline IV & I (I4.3) & $9(I 1.4)$ & $26(10.8)$ & II (6.9) & $I(3.1)$ & \\
\hline \multicolumn{7}{|l|}{ Post-bronchodilator } \\
\hline FVC, L & $3.58 \pm 0.47$ & $3.72 \pm 0.81$ & $3.35 \pm 0.85$ & $3.18 \pm 0.78$ & $2.75 \pm 0.75$ & $<0.001$ \\
\hline FVC, \% & $80.7 I \pm I I .73$ & $83.43 \pm 15.89$ & $80.91 \pm 17.35$ & $79.01 \pm 16.67$ & $75.09 \pm|3.8|$ & 0.128 \\
\hline $\mathrm{FEV}_{1}, \mathrm{~L}$ & $1.84 \pm 0.60$ & $1.81 \pm 0.68$ & $1.59 \pm 0.63$ & $1.46 \pm 0.54$ & $1.25 \pm 0.42$ & $<0.001$ \\
\hline $\mathrm{FEV}_{1}, \%$ & $50.57 \pm 17.06$ & $52.14 \pm 18.04$ & $52.17 \pm 18.56$ & $53.09 \pm 18.65$ & $55.4| \pm| 5.8 \mid$ & 0.890 \\
\hline $\mathrm{FEV} / \mathrm{FVC}, \%$ & $51.57 \pm 13.59$ & $44.77 \pm 11.04$ & $46.99 \pm 12.10$ & $46.01 \pm 11.15$ & $46.28 \pm 10.71$ & 0.625 \\
\hline \multicolumn{7}{|l|}{ Pre-bronchodilator } \\
\hline FVC, L & $3.40 \pm 0.53$ & $3.53 \pm 0.89$ & $3.19 \pm 0.88$ & $3.04 \pm 0.80$ & $2.60 \pm 0.76$ & $<0.001$ \\
\hline FVC, \% & $76.7 I \pm 12.69$ & $79.06 \pm 17.75$ & $77.01 \pm 18.32$ & $75.62 \pm 17.63$ & $71.22 \pm 15.70$ & 0.285 \\
\hline $\mathrm{FEV}_{1}, \mathrm{~L}$ & $1.76 \pm 0.61$ & $1.69 \pm 0.71$ & $1.47 \pm 0.64$ & $1.37 \pm 0.54$ & $1.17 \pm 0.40$ & $<0.001$ \\
\hline $\mathrm{FEV}_{1}, \%$ & $48.14 \pm|7.3|$ & $48.68 \pm 19.10$ & $48.29 \pm 18.88$ & $49.58 \pm 19.07$ & $51.53 \pm 14.92$ & 0.891 \\
\hline $\mathrm{FEV}_{1} / \mathrm{FVC}, \%$ & $50.86 \pm 13.07$ & $46.80 \pm 11.30$ & $46.80 \pm 11.30$ & $45.54 \pm 12.06$ & $44.86 \pm 11.23$ & 0.568 \\
\hline Positive BDR & $0(0)$ & $\mathrm{I}(\mathrm{l} .3)$ & $14(5.8)$ & $9(5.7)$ & $\mathrm{I}(0)$ & 0.621 \\
\hline History of acute exacerbation & $2(28.6)$ & $16(20.3)$ & $76(31.5)$ & $60(37.7)$ & $20(62.5)$ & $<0.001$ \\
\hline Follow-up months & $58.72 \pm 24.08$ & $63.38 \pm 31.35$ & $57.51 \pm 26.95$ & $49.93 \pm 26.66$ & $40.75 \pm 25.97$ & $<0.001$ \\
\hline
\end{tabular}

Note: Data presented as mean \pm SD or $n$ (\%).

Abbreviations: BDR, bronchodilator response; BMI, body mass index; FEV , forced expiratory volume in I-second; FVC, forced vital capacity; GOLD, Global initiative for Chronic Obstructive Lung Disease. 
Table S3 Lung function decline: 40-90 years of age

\begin{tabular}{|c|c|c|c|c|}
\hline & \multicolumn{2}{|l|}{ Unadjusted } & \multicolumn{2}{|l|}{ Adjusted } \\
\hline & Mean \pm SE & $P$-value & Mean \pm SE & $P$-value \\
\hline \multicolumn{5}{|c|}{$\mathrm{FEV}_{1}, \mathrm{~mL} /$ year } \\
\hline \multicolumn{5}{|c|}{ Post-bronchodilator } \\
\hline $40-49$ & $2.14 \pm 20.34$ & 0.123 & $-10.49 \pm 23.06$ & $0.136^{\mathrm{a}}$ \\
\hline $50-59$ & $-7.34 \pm 5.97$ & & $-7.03 \pm 6.96$ & \\
\hline $60-69$ & $-18.52 \pm 3.59$ & & $-18.65 \pm 4.09$ & \\
\hline $70-79$ & $-24.5 I \pm 4.83$ & & $-23.93 \pm 5.39$ & \\
\hline $80-90$ & $-31.44 \pm 11.89$ & & $-42.26 \pm 13.32$ & \\
\hline \multicolumn{5}{|c|}{ Pre-bronchodilator } \\
\hline $40-49$ & $3.79 \pm 20.43$ & 0.079 & $-11.08 \pm 23.47$ & $0.152^{\mathrm{a}}$ \\
\hline $50-59$ & $-2.38 \pm 5.89$ & & $-2.00 \pm 7.05$ & \\
\hline $60-69$ & $-11.49 \pm 3.58$ & & $-11.12 \pm 4.17$ & \\
\hline $70-79$ & $-21.70 \pm 4.85$ & & $-20.24 \pm 5.52$ & \\
\hline $80-90$ & $-25.16 \pm 11.94$ & & $-33.96 \pm 13.66$ & \\
\hline \multicolumn{5}{|l|}{$\mathrm{FEV}_{1}$, \%/year } \\
\hline \multicolumn{5}{|c|}{ Post-bronchodilator } \\
\hline $40-49$ & $-0.01 \pm 0.67$ & 0.015 & $-0.39 \pm 0.80$ & $0.015^{b}$ \\
\hline $50-59$ & $-0.23 \pm 0.20$ & & $-0.24 \pm 0.24$ & \\
\hline $60-69$ & $-0.62 \pm 0.12$ & & $-0.6 I \pm 0.14$ & \\
\hline $70-79$ & $-0.87 \pm 0.16$ & & $-0.83 \pm 0.19$ & \\
\hline $80-90$ & $-1.52 \pm 0.39$ & & $-2.00 \pm 0.46$ & \\
\hline \multicolumn{5}{|c|}{ Pre-bronchodilator } \\
\hline $40-49$ & $0.08 \pm 0.67$ & 0.006 & $-0.33 \pm 0.79$ & $0.020^{\mathrm{b}}$ \\
\hline $50-59$ & $-0.08 \pm 0.19$ & & $-0.07 \pm 0.24$ & \\
\hline $60-69$ & $-0.40 \pm 0.12$ & & $-0.37 \pm 0.14$ & \\
\hline $70-79$ & $-0.83 \pm 0.16$ & & $-0.75 \pm 0.19$ & \\
\hline $80-90$ & $-1.28 \pm 0.39$ & & $-1.62 \pm 0.46$ & \\
\hline
\end{tabular}

Notes: The numbers of patients within each group were as follows: 40-49 years $(n=7), 50-59$ years $(n=77), 60-69$ years $(n=241), 70-79$ years $(n=159)$ and $\geq 80$ years $(n=32)$. ${ }^{a}$ Adjusted for sex, body mass index, smoking status, bronchodilator response, experience of acute exacerbation, and initial FEV $1{ }^{\circ} A d j u s t e d$ for smoking status, bronchodilator response, experience of acute exacerbation, and initial FEV.

Abbreviations: $\mathrm{FEV}_{1}$, forced expiratory volume in I-second; SE, standard error.

\section{Publish your work in this journal}

The International Journal of COPD is an international, peer-reviewed journal of therapeutics and pharmacology focusing on concise rapid reporting of clinical studies and reviews in COPD. Special focus is given to the pathophysiological processes underlying the disease, intervention programs, patient focused education, and self management protocols.

\section{Dovepress}

This journal is indexed on PubMed Central, MedLine and CAS. The manuscript management system is completely online and includes a very quick and fair peer-review system, which is all easy to use. Visit $\mathrm{http} / / / \mathrm{www}$.dovepress.com/testimonials.php to read real quotes from published authors. 